(for example) of the effective reduction of the number of Great Powers to two.

The causes and consequences of regional differentiation can only be understood in relation to the globe viewed as an organic whole. The concept of 'global thinking' goes back among geographers to the late eighteenth century traveller von Humboldt. As thus envisaged, geography shares with sociology the methodological difficulties arising from the impossibility of isolating 'pure' problems, with the consequent need to call upon a number of diverse skills and specialisms. The present climate of thought is, however, unfavourable to group research (employing specialists from different fields) and even to team research (employing specialists within the same field), and successful examples of such work are fow. Nevertheless archæologists, historians, economists, sociologists and physical planners have recently shown an increasing disposition to seek the collaboration or advice of geographers, no doubt because, now that a second generation of trained geographers is coming to maturity, the output of work reaching an acceptable standard of scholarship is increasing. Examples of such work with a particular social bearing include analyses of the geographical circumstances of 'problem' areas - the Italo-Jugoslav boundary, Palestine, the march-lands of Russia, the 'special areas' of Britain-studies in micro-climatology, in coastal morphology, in land-utilization, areas of urban circulation and influence, and so on. The value of maps, not merely as a means of exposition, but also as a tool of research, is also increasingly appreciated.

A world war has for the second time emphasized the need for 'terrain' geography and exposed the gaps in geographical knowledge. New methods of air photography - stereoscopic survey, colour and infrared photography-are capable of supplying data by which those gaps could be rapidly filled. The interpretation of such data occupied many geographers during the Second World War. Beach reconnaissance, involving a land, sea and air complex, as a preliminary to military landings, called for novel methods of research, and led to new knowledge of shore-line processes and coastal morphology. The use of rockets and unpiloted aeroplanes lends a new importance to exact knowledge of the shape and dimensions of the geoid. The need for popular education in world geography lays upon geographers the duty of designing maps and globes which give a world picture appropriate to an 'air age'

\section{PROGRESS IN MODERN ENGINEERING}

CIVIL engineering aspects of progress in modern 1 engineering is the principal topic of the presidential address, to Section G (Engineering) by Sir William Halcrow. An analysis of engineering evolution involves cunsideration of mental conditioning in the past as well as of achievement. Society as a whole did not become mechanically minded until after the First World War, and the progress was slow. American influence is considerable, and we must understand the conditions which have led to their lavish use of machines and materials. Reference to tho progress of prime movers, of constructional materials, and of some recent developments in technique follows.

The steam engine has been highly developed for many years; but the steam railways require consider- able improvements to cater for modern traffic intensities. The great operational inflexibility of the system can only be relaxed by changes in track lay. out, signalling systems and dead weight of stock.

Steam turbines are our main prime mover for the generation of electricity. Fuel ancillaries are inherently heavy and bulky, however, and the gas turbine, which will soon be in economical operation in aircraft, may challenge the steam turbine on these grounds. At present, however, its life is too short for purely industrial purposes.

The water turbine has been highly developed for some considerable time. Intensive hydro-electric development is taking place in the Highlands of Scotland; but the great Severn Barrage tidal scheme still awaits official approval. With $800,000 \mathrm{~kW}$. installed capacity, it could produce some 2,300 million units of electricity per annum at $0 \cdot 2 d$. per unit and save one million tons of coal a year.

Our mechanical civilization did not attain a high rate of development until the latter half of the nineteenth century, when iron and steel could be produced in large quantities. The present century has seen the great development of alloy steels, and we may be approaching the end of the age of simple mild steel. The use of light alloys has greatly increased, and it is not generally realized that aluminium production depends entirely on large amounts of cheap hydro-electric power.

Modern cement dates from about 1850; and although its chemistry is still not fully understood, high grades are available in large quantities. A recent advance is the production of low-heat cement. The use of reinforced concrete is widespread, and latterly the technique of pre-stressing has resulted in considerable savings in materials in some cases.

Earthwork has only been scientifically treated since the early 1920's, when Dr. Terzaghi began to publish his penetrating analyses. Some problems still await solution, but we understand their limits and tendencies. Tunnelling is highly mechanized at present and rapid progress is possible. In soft ground, by use of a shield, a $12 \mathrm{ft}$. Tube railway tunnel in London clay can be advanced by as much as $160 \mathrm{ft}$. a week.

Prefabrication was used on a large scale for marine works during the War; for example, in the wellknown invasion harbours and the lesser-known permanent military ports in some of the Scottish sea lochs.

We have had to develop analysis by experimental methods to a considerable pitch. Electrical resistance strain gauges and photo-elastic methods are useful. In aircraft the piercing of the sonic barrier depends greatly on model and wind-tunnel research. In hydrodynamics, models are most useful for determining hull forms, wave action, silting and erosion in harbours, spillways of dams and similar problems.

\section{ANTHROPOLOGICAL APPROACH IN SOCIAL SCIENCE}

$\mathrm{N}$ his presidential address to Section $\mathrm{H}$ (Anthropology), Prof. C. Daryll Forde discusses the anthropological approach to the social sciences. The social sciences are often regarded as comprising all scholarly studies contributing to the portrayal of social conditions, including historical or descriptive accounts and those directed towards the solution of 
practical social problems. But more strictly considered, science seeks to establish valid generalizations concerning the properties of a range of natural phenomena, and its precision and explanatory value depend on the accuracy with which these properties are determined and the relations between them established. In this sense, social science must be concerned with the investigation of the nature and conditions of social relations, and should seek valid generalizations concerning variation in the social life of the human species. Interpretations of particular societies past or present, and predictions as to particular social developments in the future, depend for their penetration and ieliability on achievement in this more strictly scientific field. This dependence of advance in descriptive and practical studies on the development and application of theory is generally recognized in the field of economics, but has been less readily appreciated by students of social history, politics and ethnology.

Anthropology, traditionally concerned with the study of savage or pre-literate peoples, has developed in response to historical and practical, as well as scientific, interests. But interest in the organisation of these small-scale societies has been considerably stimulated by the hope of obtaining therefrom greater insight into problems of our own civilized societies through a better understanding of universal processes in the social life of man. The comparative study of the whole range of social forms is required for the formulating and testing of fundamental hypotheses concerning the nature of society. As in other scientific fields, advance is often easier with reference to less complicated material provided by small-scale 'primitive' societies. Moreover, the novelty and variety of institutions and social relations in such societies direct attention to problems which tend to be obscured by the particular conditions and conventional definitions current in our own society.

Anthropological studies in the field of culture have traditionally included both descriptive or ethnographic and analytical or sociological studies. It is important to recognize that as in other fields of knowledge, developments in each are interdependent. The scientific study of the social organisation of small-scale societies depends on the analysis of ethnographic data. Ethnography in turn has been rendered intrinsically more adequate and coherent by advances in sociological theory which have posed new questions and provoked new methods.

Thus earlier descriptions of societies organised in wide uni-lineal kin groups, of which only formal and ceremonial features were commonly emphasized, left obscure the processes whereby such groups were formed and maintained, and failed to reveal their role in maintaining social coherence and control among peoples where there is little specialization of activity and status. Analysis of rights and status in ritual, economic and political spheres has led to the discovery of a high degree of segmentation at a series of levels within these and other corporate bodies in other small-scale societies, and has revealed opposed tendencies to solidarity and fission within such groups as part of the adaptive character of social structure in relation to ecological conditions.

The study of corporate activity and leadership in small-scale societies shows that processes which in more complex societies are expressed in specialized religious, economic and political institutions are not absent among the former, but operate through less differentiated, multifunctional organisations. The categories of economies, religion, law and government are found to have wider reference and more variable inter-relations than is commonly recognized from the study of Western societies.

From the internal analysis of particular societies, and comparative studies, the range of conditions in which specialized institutions emerge are being more closely determined. Spencer's hypothesis of social evolution greatly stimulated the development of social anthropology in the nineteenth century. The comparative study of institutions in relation to the total social structure on one hand, and the ecological foundations of social life on the other, promises to yield a theory of social development more valid than the unverifiable speculations concerning the social conditions of early man into which interest was temporarily diverted in the nineteenth century.

\section{WIDER APPLICATIONS OF TEACHING OF PHYSIOLOGY}

$T$ HE main feature of Prof. Winifred Cullis's address to Section I (Physiology) is a plea for the training of more physiologists and a wider use of their services. Physiology, if it is to take its proper place in education, has a dual function to perform. Its importance in the teaching of medical students is well recognized; but there is too little appreciation of its other aspect as a science which, apart from its medical bearing, is important for the general health of the community. A plea for a wider recognition of this aspect was chosen for the address, not only because Prof. Cullis's war-time experience broke her contact with the more academic side of physiology, but also because in her opinion it is one insufficiently recognized and one in which she is able to draw upon personal experience.

The community owes much to physiology and is interested in hearing of this debt. The newer knowledge of nutrition, with which will always be associ ated the name of Sir Frederick Gowland Hopkins, has shown its use in dealing with the restrictions imposed by war-time conditions. The story of insulin, itself of great interest, has a special value in these days of popular writings, in giving some idea of the time that may elapse between the making of a discovery and its safe and general application. The decision of the men of Smithfield not to increase the price of pancreatic material, after hearing what this material could mean in giving to diabetic patients the chance of an active life, is a dramatic instance of the value of knowledge. Possibly, too, a better knowledge of physiological principles might enable the public to evaluate more correctly some of the fantastic claims made in advertisements of certain preparations.

Well-qualified teachers of physiology would be of use in many directions. They are much needed in the general training colleges as well as in those devoted to the training of teachers of domestic science and of physical training. They would be of great value in schools in the upper forms, where they could build upon the foundations often so well laid in the junior forms by good biology teaching. In these institutions and in industrial establishments they could be of use in collecting the normal physiological data now recognized as necessary in the departments 